\title{
The Association between Increased Body Mass Index and Overuse Injuries in Israel Defense Forces Conscripts
}

\author{
Netanel A. Hollander ${ }^{a, b}$ Aharon S. Finestone ${ }^{a, c}$ Victoria Yofe ${ }^{a}$ \\ Tarif Bader ${ }^{a}$ d $\quad$ Racheli Magnezi ${ }^{b}$ \\ a Surgeon General's Headquarters, Israel Defense Forces, Ramat-Gan, Israel; bepartment \\ of Management, Health System Management Program, Bar Ilan University, Ramat-Gan, \\ Israel; ' ${ }^{\circ}$ Department of Orthopedic Surgery, Shamir Medical Center affiliated to the Faculty \\ of Medicine, Tel Aviv University, Zerifin, Israel; ${ }^{d}$ Department of Military Medicine, Hebrew \\ University, Jerusalem, Israel
}

\section{Keywords}

Overuse injury $\cdot$ Military $\cdot$ Body mass index $\cdot$ Obesity

\begin{abstract}
Objectives: To examine the association between body mass index (BMI) and overuse injuries (OI) among Israel Defense Forces soldiers, in different corps. Methods: Conscripts between 2003 and 2012, infantry, armored corps and intelligence corps (controls) were studied. Ol data were taken from computerized patient records. The BMI was classified as underweight, lownormal (18.5-21.9), high-normal (22-24.9), overweight and obese. Multivariate analysis was performed using logistic regression. Results: There were 73,640 soldiers: 42,506 infantry, 20,781 armor and 10,353 intelligence. Ol rates were 52.2, 51.6 and $27 \%$, respectively. OI rate was directly proportional to $\mathrm{BMI}$ in all groups (relative risk compared to low-normal, underweight: 0.97 , high-normal: 1.05, overweight: 1.11, obese: 1.19, $p<0.05$ for all), increased height and younger age. By logistic regression, OI were significantly associated with training group, higher BMI, increased height, younger age, lower education, lower socioeconomic status and lower psychotechnical grading. Throughout the BMI range, each additional unit of BMI was associated with a $2 \%$ Ol increase. Conclusions: Higher BMI was associated with a higher rate of $\mathrm{Ol}$ in all groups. Therefore there is no point in differentially assigning recruits based on BMI.

Netanel A. Hollander and Aharon S. Finestone contributed equally to this work. This research was prepared by Netanel A. Hollander in partial fulfillment of the requirements for the Master's Degree in the Health System Management program in the Department of Management, at the Bar Ilan University, Ramat Gan, Israel. 
Hollander et al.: Body Mass Index and Overuse Injuries in Israel Defense Forces

\section{Introduction}

Overuse injuries (OI) are defined as injuries caused by repetitive, submaximal loading of the musculoskeletal system, when there is insufficient rest for recovery and adaptation of the tissues [1]. OI are a major cause for loss of training days [2-4] and medical attrition among combatants [5]. Beyond the personal effect on the soldier, their consequences have high economic costs and may even compromise the army's preparedness for combat $[4,6$, 7]. Identifying risk factors for these injuries could be important in reducing their incidence if interventions are applicable [6]. In certain constellations, a particularly high risk ratio might justify disqualifying certain candidates from certain training programs. Various risk factors for OI have been found, including older age, smoking, poor aerobic endurance, low muscular strength and high fat percentages, but many of the reports are contradictory [6, 8-10].

Physiologically, the body can be divided into 2-4 compartments. The simplest model includes fat and lean body mass [11]. While some fat is necessary as an energy store, it does not contribute to physical activity. Excess fat increases the load on all other tissues [12], beyond the well-known deleterious effect of excessive weight/fat on many physiological systems in the body [13-21]. Furthermore, children with obesity may be at higher risk of injury as passengers in motor vehicle crashes [22]. While the body mass index (BMI) has some limitations, it is accepted as a reliable and simple measure for evaluating overweight in large populations and is used internationally $[23,24]$. Associations between BMI and injuries have been reported, but the data are inconclusive. In the Canadian population, the BMI was associated with injuries in women, but not in men [25]. In a review of the literature on injury risk factors for US military combat training, mixed evidence was found regarding the association between BMI and injuries in males [6]. Data from conscripts in the Finnish army show a U-shaped curve with more injuries in the underweight and overweight groups [24]. However, no such association was found in the Greek army, which also has conscription [8]. Other studies showed that evidence of injury risk factors found in one army are not necessarily relevant to other armies. This is because of differences in populations between armies, training programs and in databases [8, 9, 26-28].

The Israel Defense Forces (IDF) have characteristics that may affect the association between BMI and OI. The proportion of overweight and obesity among IDF conscripts is 12.4 and $4 \%$, respectively [26], compared with 47 and 13\% among US army soldiers [27]. Other differences between these two armies are the average age of soldiers, 20.1 years in the IDF [29] and 27.1 years in the US army [28], and the fact that the IDF has conscripts and the US army enlists volunteers.

OI are common among IDF combatants. Among the $3.4 \%$ who drop out due to medical problems, $43 \%$ are for orthopedic reasons, $90 \%$ of which were defined as OI. Common sites of OI are the lower back (27\%), the ankle and foot (23\%), and the knee (21.5\%) [7]. The basic training of an infantry soldier in the IDF lasts 3 months, compared with 2 months in armored corps (including artillery). The nature of training and operational activity in the infantry is characterized by long marches carrying heavy equipment, as opposed to more vehiclemounted activity and the lifting of ammunition in armor [7].

The relationship between BMI and OI in the IDF has not yet been examined, nor has there been a comparison between different corps with varying physical requirements. Based on the higher training demands in infantry, it is axiom that there are more injuries in infantry, at least during the training phase. To decrease injury and attrition rates, recruits profiled with a mild medical condition are assigned to armor units and not to infantry. Our hypothesis was that increased BMI would be related to a higher OI rate in the infantry, compared with armor soldiers. If this was found to be true, it might make sense to add BMI to the profiling system 
Hollander et al.: Body Mass Index and Overuse Injuries in Israel Defense Forces

so as to preferentially assign recruits with a high BMI to non-infantry units, aimed at potentially reducing injury rates. This study examined the connection between BMI and OI among IDF combat soldiers, in different corps.

\section{Methods}

Data were collected from the IDF Computerized Patient Record (CPR) and from the IDF general manpower database.

\section{Population}

Inclusion criteria were males, aged 18-25 years, inducted from January 1,2003, to December 31,2012 , for 3 years of compulsory military service (this was reduced to 32 months in July 2015; the starting date was after the CPR had become operational in all relevant units). This population includes mainly Jews and 2-3\% citizens in minorities (Druse, Cherkess and others). The Jewish male soldiers in the IDF represent about $70 \%$ of the male Jewish citizens of conscript age. Ultraorthodox Jews (13\%) are exempt due to their religion. The remaining $17 \%$ of the Jews are exempt for medical and psychosocial reasons. Arab Moslems (about 21\% of Israeli citizens at conscript age) are also exempt. IDF combat training units were classified into infantry (INFAN) and armor (ARMOR). Soldiers were included in a group if they were assigned to one of these corps training units for at least 2 weeks. Soldiers were excluded if they were assigned to special forces or elite infantry (these units have a physical sorting process which can cause a problem of overmotivation), combat engineering (not clearly classified as infantry or armor) and mixed gender units (the level of physical training is adjusted to a level appropriate for women). As this study focused on IDF conscripts, generally known to have a high level of utilizing medical services [29], a further control group of intelligence (INTEL) soldiers was analyzed. As a big data study, the diagnosis of OI is based on the diagnoses coded by the examining physicians, and these diagnosis codes are included in the diagnostic algorithm. There is obviously some overlap between actual OI and musculoskeletal complaints that might not be related to overuse. The importance of this control group, not subjected to significant training that might be labeled overuse, is that is gives an idea regarding the magnitude of the diagnoses not actually related to overuse.

\section{Training}

In INFAN, the physically demanding training with running and marches includes 3 months basic training and 4 months advanced training. The physical aspects of the training include marches, open area training and formal physical training sessions. The marches are once every 1 or 2 weeks, increasing in length gradually over the 7 months from $3 \mathrm{~km}$ to about $70 \mathrm{~km}$ with recruits carrying up to $40 \%$ bodyweight. Open area storming includes several weeks throughout the 7 months, training as singles, links, squads, platoons and eventually companies (each level repeated as many times as necessary to get it correct without firing, and then with live fire). Formal physical training sessions (3 times a week, 75 min each) include running and physical training for strength and flexibility. In ARMOR, the physically demanding training with running and marches lasts for 2 months, followed by 5 months of task-related training. During the 7 months they perform 2 weekly 75 -min sessions of running and physical training for strength and flexibility. INTEL are non-combat soldiers who do a basic training for about 3 weeks with very limited physical demands. There are no differences between the training programs for subjects based on their body weight or BMI. In ARMOR during the task-related training, soldiers with lower physical ability (based on their running score, medical limitation or absenteeism) train separately to improve their success at the final physical fitness score. In both INFAN and ARMOR, soldiers failing the final fitness tests might 
be detained in the basic training base for further physical training until they succeed. Based on the directives of the IDF Combat Fitness Department, there were no significant changes to the training programs during the period included in the study.

\section{Data Collection}

At the age of 17, service-eligible Israeli citizens are called up for a medical examination to assess their suitability for military service. The examination includes weight (to the nearest kilogram) and height (to the nearest centimeter) measured by trained medics on a beam balance and stadiometer with each participant barefoot and wearing underwear only. A recent IDF study compared the height and weight at induction to the recruitment office measurements [30]. The mean time between measurements was 577 days (range 474-731). Well-known increases in all parameters were reported (height $1.6 \mathrm{~cm}$, weight $2.7 \mathrm{~kg}$, BMI 0.97 ) but $97.4 \%$ of those categorized as normal BMI during the first encounter were normal at induction. Data regarding age, psychotechnical grading, socioeconomic status based on residential location and other factors, education and country of origin were recorded.

\section{OI Definition}

A soldier was defined as injured based on a modification of the standard IDF OI algorithm which is based on the CPR (Fig. 1). Diagnoses in the CPR are entered by primary physicians, specialists and physiotherapists. According to the modified algorithm, a soldier is classified as injured if he fulfills at least 1 of 3 criteria:

(a) Medical board decision profiling the soldier, based on a list of profiles related to OI, severe enough to prevent combat training. An IDF medical board includes military physicians with extra training on the IDF medical classification system, and it bases its decisions on recommendations from specialists who have examined the soldier. The profiles include a code given to a diagnosis (or group of diagnoses) and a severity level which corresponds to the soldier's potential for military service (infantry, non-infantry combat, non-combat, not suitable for any military service). Both permanent and temporary codes were counted. An example of the codes for back diagnosis has been published [31].

(b) A relevant diagnosis in the CPR with duty limitation. All 7,165 possible diagnoses in the CPR were reviewed, and 357 diagnoses related to OI were included. These were mainly diagnoses related to the extremities and musculoskeletal torso, excluding traumatic injuries such as fractures. During the same medical encounter, the soldier had to be prescribed duty restriction: 3 days or more of complete rest, or 5 days or more of relevant exemption (e.g., limited weight carrying for an ankle sprain).

(c) The soldier had an operation or another procedure relevant to an OI.

\section{Research Variables}

Independent variables were age, height, BMI (weight in kilograms divided by height in meters squared). The BMI was classified according to a modification of the World Health Organization subgroups: BMI <18.5 (underweight), $18.5 \leq$ BMI < 22 (low-normal BMI; reference), $22 \leq \mathrm{BMI}<25$ (high-normal BMI), $25 \leq \mathrm{BMI}<30$ (overweight) and BMI $\geq 30$ (obese). The subdivision of the normal range was made given its broad range and previous evidence showing that cardiovascular and other morbidity and mortality increase within the upper normal BMI range [15-18, 23, 24]. Psychotechnical grading was graded from 10 to 90, in intervals of 10. Socioeconomic status was defined from level 1 to 10 and grouped: 1-3 low, 4-7 middle (reference) and 8-10 high, based on the Israel Central Bureau of Statistics, mainly according to residential location [32]. Education was divided into 3 groups: 12 years of schooling (reference), under 12 and above 12. Types of training were INFAN, ARMOR and INTEL (reference for comparing INFAN and ARMOR). 


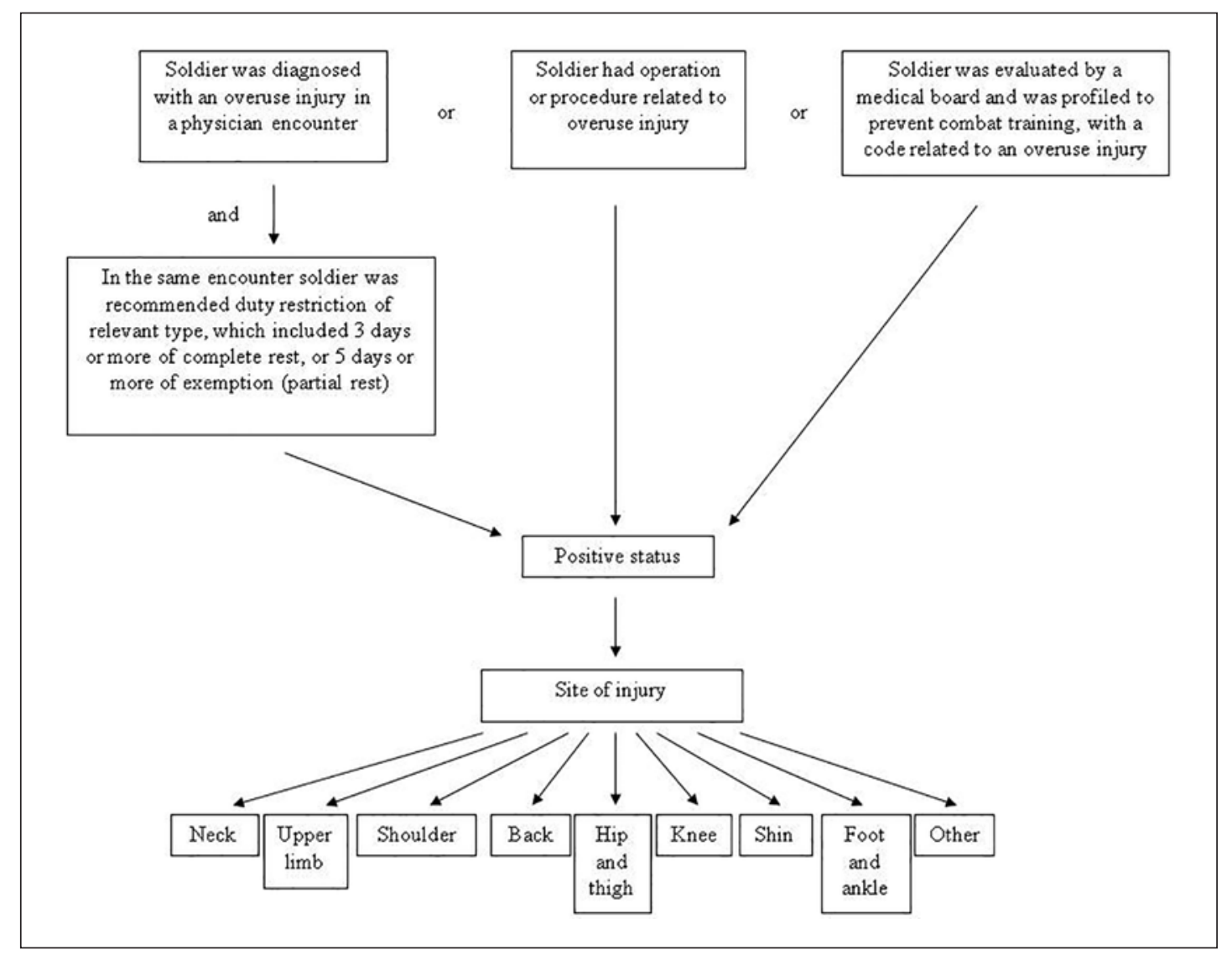

Fig. 1. The modified Israel Defense Forces (IDF) algorithm for defining overuse injuries based on the Computerized Patient Record and IDF general manpower database.

Dependent variables of OI were divided into 9 subgroups by region: neck, shoulder, upper limb, back, hip and pelvis, knee, shin, foot and ankle, and other.

\section{Data Analysis}

Analyses were based on the number of soldiers coded for a given injury. As a soldier can have more than one injury, the total injury rate is not the arithmetical sum of the subgroups. The statistical analysis was performed using SAS (version 9.4, SAS Institute Inc., Cary, NC, USA). Statistical significance was set at $p<0.05$. Univariate analysis was performed using the $\chi^{2}$ test, the Cochran-Armitage test for trend and ANOVA with Duncan's post hoc test for comparing group effects. Multivariate analysis was performed using logistic regression both using BMI as an interval variable and comparing the abnormal groups to the low-normal (each analysis separately). All statistical tests were two-tailed.

\section{Results}

Based on the inclusion criteria, we found 73,640 soldiers: 42,506 INFAN, 20,781 ARMOR and 10,353 INTEL. The average age (standard deviation) of the study population at induction was 18.9 years (1.1), the BMI was 21.6 (4.3), psychotechnical grading 57.4 (19.0) and socioeconomic status 5.9 (1.7). Demographic data by training group are presented in Table 1. 
Fig. 2. Overuse injuries by age. Rate and 95\% confidence interval. The trend to decrease with age was significant $(p<0.001$, Cochran-Armitage test for trend). Total subjects in sample 73,640. Note higher variance in older ages due to considerably fewer soldiers. When separated by training group (graphs not presented), the significance was also $p<0.001$ for each group.

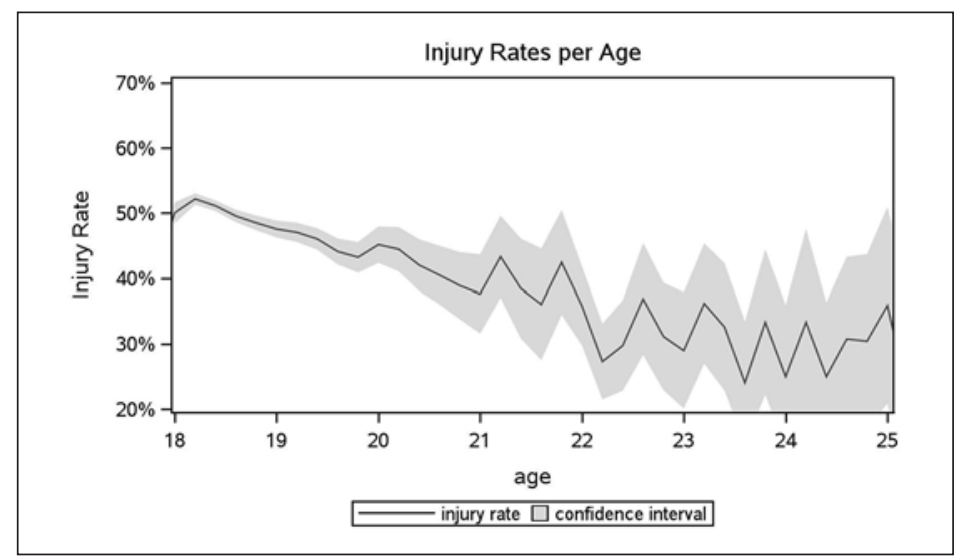

Table 1. Demographic data by training group

\begin{tabular}{|c|c|c|c|c|c|}
\hline Variable & $\begin{array}{l}\text { Infantry } \\
(n=42,506)\end{array}$ & $\begin{array}{l}\text { Armor } \\
(n=20,781)\end{array}$ & $\begin{array}{l}\text { Intelligence } \\
(n=10,353)\end{array}$ & $\begin{array}{l}\text { Total } \\
(n=73,640)\end{array}$ & $p$ value \\
\hline Age, years & $\begin{array}{l}18.9(1.1) \\
\mathrm{A}\end{array}$ & $\begin{array}{l}18.8(1.1) \\
\mathrm{B}\end{array}$ & $\begin{array}{l}19.1(1.4) \\
C\end{array}$ & $18.9(1.1)$ & $<0.0001$ \\
\hline Height, $\mathrm{cm}$ & $\begin{array}{l}171.8(20.9) \\
\mathrm{A}\end{array}$ & $\begin{array}{l}173.4(14.5) \\
B\end{array}$ & $\begin{array}{l}174.7(11) \\
C\end{array}$ & $172.7(18.2)$ & $<0.0001$ \\
\hline Weight, kg & $\begin{array}{l}66.8(14.6) \\
A\end{array}$ & $\begin{array}{l}68.2(14.4) \\
B\end{array}$ & $\begin{array}{l}67.5(13.3) \\
C\end{array}$ & $67.3(14.4)$ & $<0.0001$ \\
\hline BMI & $\begin{array}{l}21.5(4.4) \\
B\end{array}$ & $\begin{array}{l}21.9(4.3) \\
A\end{array}$ & $\begin{array}{l}21.5(3.9) \\
B\end{array}$ & $21.6(4.3)$ & $<0.0001$ \\
\hline Psychotechnical grading & $\begin{array}{l}53.5(18.5) \\
\text { A }\end{array}$ & $\begin{array}{l}58.1(18.4) \\
B\end{array}$ & $\begin{array}{l}72.2(14.7) \\
C\end{array}$ & $57.4(19)$ & $<0.0001$ \\
\hline Socioeconomic status & $\begin{array}{l}5.7(1.7) \\
\mathrm{A}\end{array}$ & $\begin{array}{l}6.1(1.6) \\
B\end{array}$ & $\begin{array}{l}6.5(1.7) \\
C\end{array}$ & $5.9(1.7)$ & $<0.0001$ \\
\hline
\end{tabular}

Armor includes artillery. Results are expressed as means (standard deviation). Psychotechnical grading 10-90. Socioeconomic status by area of residence graded 1-10. $p$ by analysis of variance. Groups are not statistically different at the 0.05 level if the same letter appears under both values.

The overall rate of OI during 3 years of military service was $48.5 \%$ (INFAN: $52.2 \%$, ARMOR: 51.6\% and INTEL: $27.0 \%$ ), the OI rate was inversely proportional to age (Fig. 2). Soldiers who enlisted at the age of 18 had the highest rate of injuries, with less in the 19-yearolds, followed by the 20 -year-olds and the ones aged $21+$ with the lowest rate. These were the relations in all groups with exception of ARMOR, where the injury rate in the 19-year-olds was slightly higher than in the 18-year-olds.

The OI rate was directly proportional to BMI in all training groups $(p<0.0001$, Fig. 3). Univariate comparisons of the relative risk in the underweight, high-normal, overweight and obese groups compared to the low-normal weight group broken down by training groups are presented in Table 2. By logistic regression with BMI as an interval variable, we found that throughout the BMI range, each additional unit of BMI was associated with a $2 \%$ increase in OI. 
Fig. 3. Overuse injuries by BMI group and training group. Rate and 95\% confidence intervals. For each training group, $p<0.001$ for trend over the BMI group (Cochran-Armitage test for trend). Total subjects in sample 72,934 (infantry 41,942, armor 20,667, intelligence 10,325).

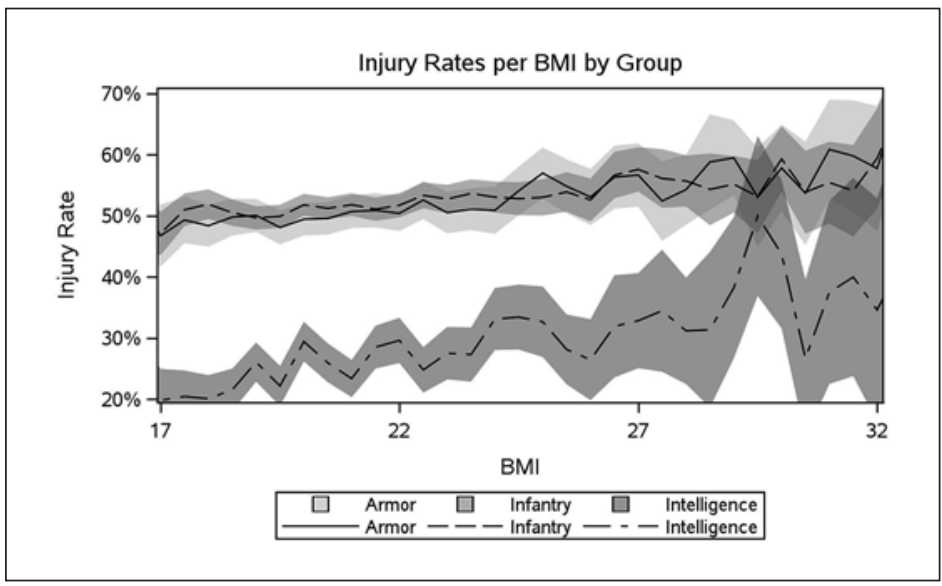

Table 2. Univariate analysis of relative risk (RR) and 95\% confidence interval (CI, Wald) for overuse injury (OI) in comparison to low-normal BMI for each training group

\begin{tabular}{|c|c|c|c|c|c|}
\hline & Underweight & Low-normal & High-normal & Overweight & Obese \\
\hline \multicolumn{6}{|c|}{ Infantry $(n=41,942)$} \\
\hline \multirow[t]{2}{*}{ Injured } & 2,284 & 9,495 & 5,784 & 3,319 & 1,014 \\
\hline & $50.51 \%$ & $50.91 \%$ & $52.86 \%$ & $54.71 \%$ & $57.55 \%$ \\
\hline Total & 4,522 & 18,649 & 10,943 & 6,066 & 1,762 \\
\hline $\mathrm{RR}$ & 0.9920 & 1.0 & 1.0381 & 1.0746 & 1.1303 \\
\hline $95 \% \mathrm{CI}$ & $0.9607-1.0244$ & ref. & $1.0149-1.0619$ & 1.0461-1.1039 & $1.0833-1.1794$ \\
\hline$p$ & $6.3 \times 10^{-1}(\mathrm{~ns})$ & ref. & $1.3 \times 10^{-3}$ & $2.6 \times 10^{-7}$ & $1.1 \times 10^{-7}$ \\
\hline \multicolumn{6}{|c|}{$\operatorname{Armor}(n=20,667)$} \\
\hline \multirow[t]{2}{*}{ Injured } & 1,128 & 4,417 & 2,591 & 1,805 & 719 \\
\hline & $48.92 \%$ & $49.81 \%$ & $51.49 \%$ & $55.57 \%$ & $59.27 \%$ \\
\hline Total & 2,306 & 8,868 & 5,032 & 3,248 & 1,213 \\
\hline $\mathrm{RR}$ & 0.9821 & 1.0 & 1.0338 & 1.1157 & 1.190124 \\
\hline $95 \% \mathrm{CI}$ & $0.9373-1.0290$ & ref. & 0.9992-1.0695 & $1.0750-1.1580$ & $1.1308-1.2525$ \\
\hline$p$ & $4.5 \times 10^{-1}(\mathrm{~ns})$ & ref. & $5.7 \times 10^{-2}$ & $1.9 \times 10^{-8}$ & $5.8 \times 10^{-10}$ \\
\hline \multicolumn{6}{|c|}{ Intelligence $(n=10,325)$} \\
\hline \multirow[t]{2}{*}{ Injured } & 292 & 1,210 & 731 & 413 & 146 \\
\hline & $22.00 \%$ & $25.48 \%$ & $28.86 \%$ & $31.97 \%$ & $34.43 \%$ \\
\hline Total & 1,327 & 4,749 & 2,533 & 1,292 & 424 \\
\hline $\mathrm{RR}$ & 0.8636 & 1.0 & 1.1327 & 1.2546 & 1.3515 \\
\hline $95 \% \mathrm{CI}$ & $0.7718-0.9663$ & ref. & $1.0475-1.2247$ & $1.1429-1.3772$ & $1.1748-1.5546$ \\
\hline$p$ & $9.5 \times 10^{-3}$ & ref. & $2.0 \times 10^{-3}$ & $4.1 \times 10^{-6}$ & $8.6 \times 10^{-5}$ \\
\hline \multicolumn{6}{|c|}{ All $(n=72,934)$} \\
\hline Injured & $45.42 \%$ & $46.87 \%$ & $49.20 \%$ & $52.21 \%$ & $55.28 \%$ \\
\hline $\mathrm{RR}$ & 0.97 & 1.0 & 1.05 & 1.11 & 1.19 \\
\hline $95 \% \mathrm{CI}$ & $0.94-0.99$ & ref. & $1.03-1.06$ & $1.09-1.14$ & $1.14-1.23$ \\
\hline$p$ & 0.02 & ref. & $4.2 \times 10^{-7}$ & $1.5 \times 10^{-21}$ & $1.0 \times 10^{-20}$ \\
\hline
\end{tabular}

$p$ value for two-sided Fisher's exact test. Low-normal, BMI 18.50-21.99; high-normal, BMI 22.00-24.99.

On multivariate analysis, combat training was associated with a considerably higher risk of OI than intelligence was. There was no difference between INFAN and ARMOR. Significant and incremental increases in OI were found between high-normal, overweight and obese compared to the low-normal weight reference (main multivariate model results, odds ratios and confidence intervals are presented in Fig. 4). The underweight had significantly fewer OI 


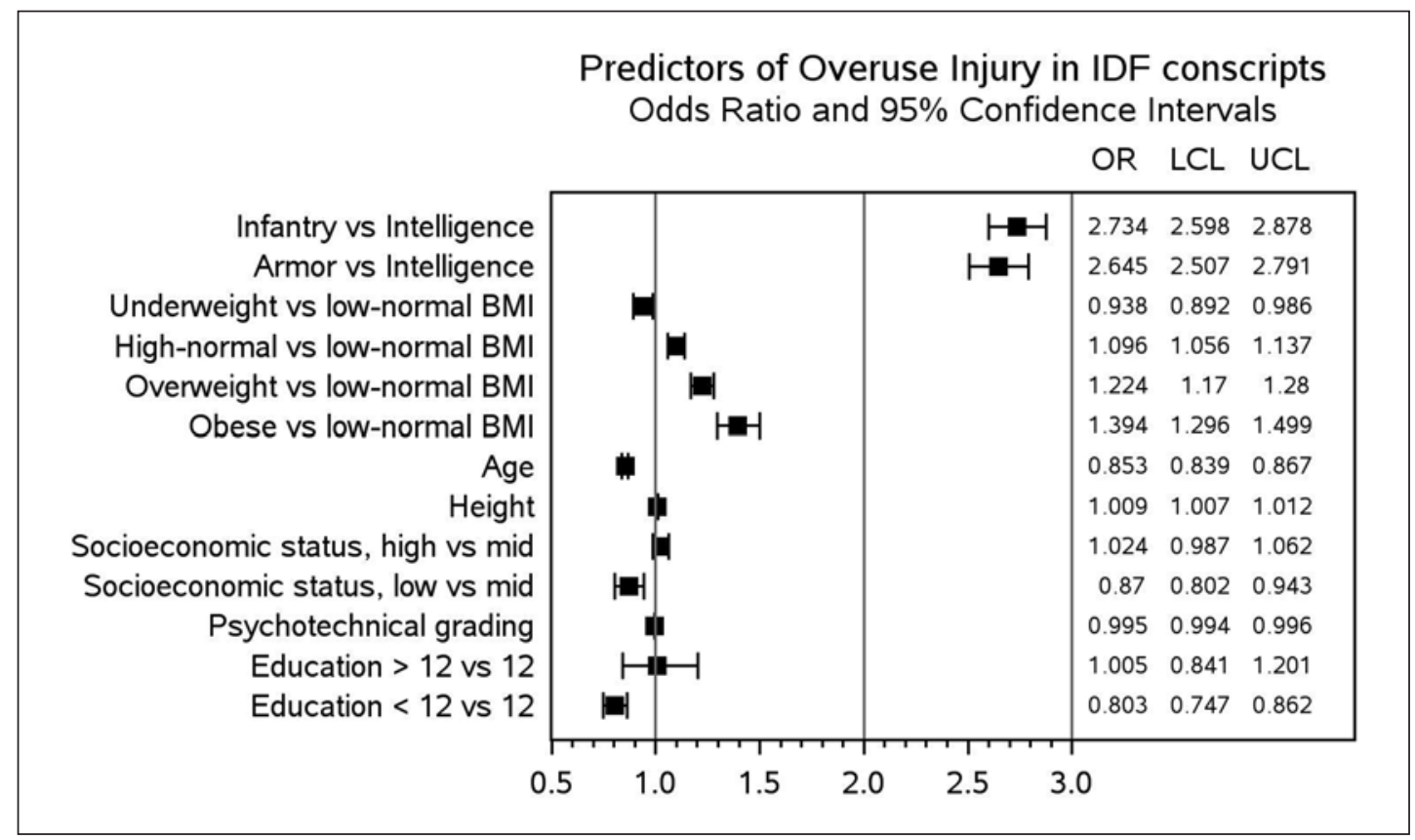

Fig. 4. Predictors of overuse injuries by multivariate analysis (logistic regression). Independent variables listed were significant at $p<0.0001$, training in infantry or armored corps (including artillery) versus intelligence, all groups of BMI compared with low-normal (18.5 $\leq$ BMI < 22), age, height, low socioeconomic status, psychotechnical grading and less or more than 12 years' education compared with 12 years' education. $\mathrm{OR}$, odds ratio; LCL, lower confidence limit; UCL, upper confidence limit.

than the low-normal BMI recruits did. Older age at induction was significantly associated with a lower rate of OI. Height, psychotechnical grading and socioeconomic status had minimal effects albeit statistically significant as did all other variables in the model at the $p<0.0001$ level. When grouped according to type of training, a significant association was found between overweight and obesity and OI in all three groups, and between high-normal and OI in INFAN and INTEL. Older age at induction was significantly associated with a lower rate of OI in all groups.

When broken down by body region, the main regions with OI were the back (16.5\%), knee (15.4\%), and foot and ankle (13.4\%). In these regions, OI were associated with higher BMI. Contrarily, OI in the shin were associated with lower BMI. The main multivariate model results according to training group for the different body regions are summarized in Table 3 .

We found a limited positive correlation between date of induction and BMI (Pearson, $R=$ $0.07, p<0.001$, i.e. increasing BMI over time), but a negative relationship between date of induction and OI ( $t$ test, $p<0.001$, i.e. the injured had been inducted just over 6 months later). As these findings seemed to contradict themselves, these variables were not included in the multivariate model.

\section{Discussion}

While the final goal in identifying risk factors for injury is prevention, this may be achieved by 1 of 3 intermediates: (a) finding causes that can be modified; (b) finding unmodifiable causes that might justify disqualifying someone from participation in a program with 


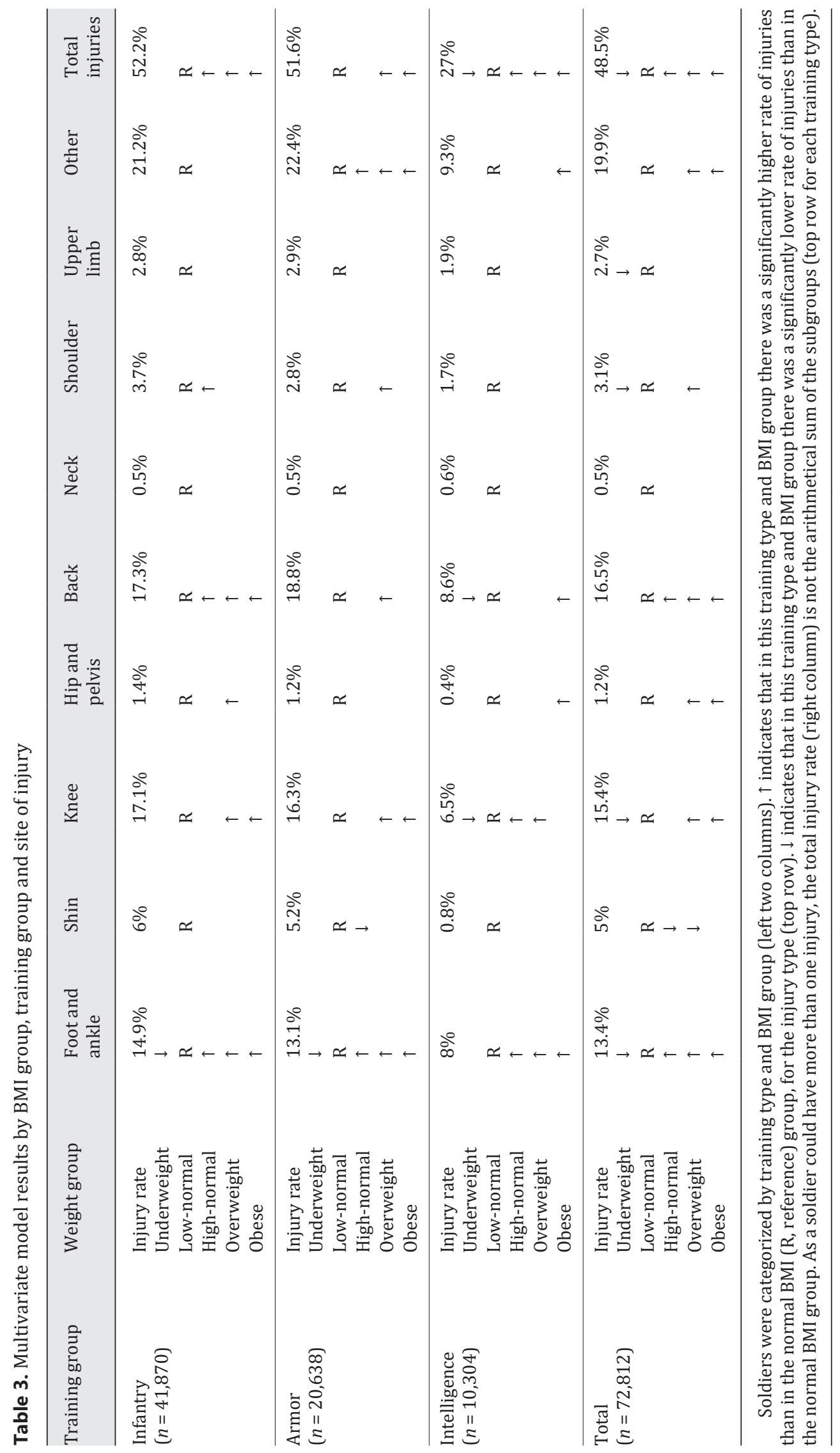


risk; (c) adding to the body of scientific knowledge on the risk factor or the injury. While we would like to think obesity is modifiable it is unlikely that such modifications would be relevant for OI prevention in conscripts. The purpose of our study was to compare OI rates in INFAN versus ARMOR under the hypothesis that the more strenuous training and service in INFAN might put subjects with obesity at an unreasonable risk. This might result in a recommendation to preferentially assign recruits with obesity to ARMOR (as is done for recruits with many mild medical problems). Our data clearly support not doing this. Current IDF criteria for exclusion from combat units for overweight are based on a BMI of around 36. Data from this study do not support this cutoff point based on OI. Other parameters in the group with obesity, including manpower availability and attrition should also be taken into account, but they were beyond the scope of this study. If other armies found similar results to those we have presented, they might also consider modifying their weight standards. But the US Army has failed to meet its recruiting quota for several years now. As a result, enlistment criteria have been slackened, and recruits do not need to meet the US Army weight standards at induction, but they have 180 days to do so. Under these circumstances, the low increased risk ratios for OI found in this study would probably not justify a change of policy.

Obesity is clearly detrimental to many aspects of health $[13,14]$ and is increasing [33]. In this study, we demonstrated that there was a direct and highly statistically significant correlation between the modified classical BMI grouping (underweight, low-normal, high-normal, overweight and obese) and OI among a large cohort of IDF conscripts. Previous studies on other populations have been somewhat inconclusive.

A possible explanation for the higher OI rate in overweight subjects might be some predisposition to both obesity and to injury. Examples of feasible intermediaries that might predispose for both could be developmental coordination disorder [34], attention deficit disorder [35] and lower education levels as found both in German conscripts and in the Finnish study (lower education was related to high obesity levels and more injury) $[24,36]$. Our multivariate analysis corrects for education. It is also possible that because of the prejudice in society against overweight people it may predispose military staff to have negative associations with overweight recruits and lead to their higher failure rates, associated with injuries.

Our reported rates of OI (52\% in combatants, $27 \%$ in controls) might seem high. In fact, as the controls did next to no physical activity as part of their military duties, and only a very small proportion of the non-combat soldiers are physically active enough in their spare time to get injured, the diagnoses captured by the algorithm must include musculoskeletal complaints not necessarily related to overuse. The previous IDF algorithm had even wider inclusion criteria. It included referral to an orthopedic surgeon, to a physiotherapist or for relevant imaging or a prescription for an orthotic device. These criteria did not necessitate activity restriction. Applying this wider algorithm to our population produced an OI rate for combatants of $83.5 \%$. Using the present algorithm (Fig. 1) our $52 \%$ OI rate in 3 years of combatant military training and service seems reasonable, and certainly compares well with the US military $62 \%$ during 1 year of duty [37] and Finnish data of 51\% (78\% including acute injuries) in 180 days of training [9]. From our database, it is not possible to differentiate acute injuries from OI as the Finnish did in their prospective study, even though they included sprains and dislocations etc. among acute injuries whereas in this and most other IDF studies these were included as OI but fractures were excluded (acute fractures account for less than $2 \%$ of IDF injuries) [38]. Our data also seem in line with the results from Kaufman's review of $6-12 \%$ OI per month [39].

Many of the so-called injuries in these studies are "pain injuries." But if the pain brought the soldier to the physician, and the physician prescribed duty limitations (which are our 
main inclusion criterion for injury), it is relevant for both military and general epidemiological health aspects. Subjects with obesity may be more prone to pain, although the relationship between the 2 conditions is not clear [40,41]. On the other hand, if overweight patients seeking more medical attention for pain receive a recommendation to refrain from activity, this may even be a mechanism by which the medical profession is inadvertently hindering the efforts to increase personal activity. The similar pattern of OI in the control group may support the generalizability of this concept.

The relationship we found between injuries and BMI groups was linear (Fig. 4) and not a U-shaped curve as described by Taanila et al. [24] in Finland and others. Underweight, based on BMI, could represent muscle depletion. Muscle tissue not only helps to cope with loads but is a protective factor against injuries [10]. The BMI therefore constitutes a problematic indicator in this respect [42]. A new initiative in the IDF is for units that allocate carried weight based on body weight to base the carried weight allocation on lean body mass to try to prevent injuries [43].

Division of OI by regions of the body shows that most injuries were to the back and lower extremities, as could be expected and has been reported frequently $[9,38]$, but different from the Finnish data [24]. The BMI seems to affect areas of the body differently. In the knee, foot and ankle, a high BMI was associated with a high rate of OI. These associations may be due to a long torque arm that the body mass has on the lower extremities. However, the shin, which is anatomically between these regions, did not have such associations, as Knapik et al. [44] found. Milgrom et al. [45] found tibia stress fractures in IDF elite infantry recruits to be related to low tibia length and width, these not being affected by weight in their cohorts [46]. The difference may be due to the fact that the shin is not an articular region, and therefore the forces acting on it have a different effect than on the joint areas. Injuries of the shin are also dependent on running, and recruits with higher BMI may have less ability to run. Furthermore, the back, which is also an articular region, was significantly affected by BMI, even though it is close to the center of mass and has a shorter torque arm on it compared to the lower extremities. Our data also support the recommendation of Twig et al. [18] to divide the normal BMI group into 2 (low-normal less than 22 and high-normal $\geq 22$ ).

The limitations of this study are its retrospective nature, the lack of covariates, the known problems using BMI to represent the level of obesity/adiposity, and the time between the measurement of height and weight and induction. Furthermore, since this study was initiated, data on Hellenic Army Academy cadets demonstrated that body fat percentage values are more sensitive indicators for musculoskeletal injuries than BMI [47]. Serious problems arise from using clinical coding used for treating patient complaints to study epidemiology. This is more so with musculoskeletal complaints where there is overlap between possible injuries and complaints not necessarily related to activity, or possibly related to inactivity in intelligence soldiers sitting many hours in front of computer screens. This is further complicated by the high rate of "other" for the OI region. The latter is, in fact, related directly to the ability of the physician to encode the diagnosis: "Pain in limb" (ICD-9 - 729.5). While we have no concrete data on other health care systems, it would seem that this problem is not unique to the IDF ("Pain in unspecified limb" is a valid ICD-10 code - M79.609). This diagnosis should probably be removed from the list of diagnoses available to clinicians, forcing them to be more explicit. It is debatable whether ankle sprains and shoulder dislocations should be classified as OI. Our rationale was that these injuries are preventable by appropriate training, and therefore we included them as OI. A further limitation is that the IDF medical criteria for inclusion in the control group (intelligence) are different from those of combat soldiers, including more comorbidities we could not correct for. While it may be possible to extrapolate from our data to other military populations, 
particularly conscripts, there are certainly no data in the literature that would allow for extrapolation to a civilian population.

\section{Conclusions}

Obesity, as measured by BMI, is directly related to OI in IDF conscripts regardless of the type of training they do. From these findings we conclude that assigning conscripts to combat units should not be restricted by BMI. We join the recommendation of Twig et al. [18] to divide the normal BMI into low-normal and high-normal, and to use the low-normal as the reference group. Underweight was a protective factor for OI. Hence, we recommend further research on the influence of low BMI on different health variables. Health care systems interested in enabling Big Data research should pay more attention to their coding system for musculoskeletal complaints and invest in the clinician computer interphase to improve the coding.

\section{Statement of Ethics}

This study was approved by the IDF institutional review board, approval No. 1604-2015.

\section{Disclosure Statement}

The authors declare that they have no conflict of interest.

\section{Funding Sources}

No financial support/funding was received for this study.

\section{Author Contributions}

N.A.H. conceptualized and collected the data for the study and compiled the manuscript draft. A.S.F. designed the study, analyzed the data and finalized the manuscript. V.Y. collected the data and performed the analysis. T.B. and R.M. assisted in designing the study and in the critical review of the manuscript. All authors approved the final version of the paper as submitted.

\section{References}

1 DiFiori JP, Benjamin HJ, Brenner JS, Gregory A, Jayanthi N, Landry GL, et al. Overuse injuries and burnout in youth sports: a position statement from the American Medical Society for Sports Medicine. Br J Sports Med. 2014 Feb;48(4):287-8.

2 Cowan DN, Bedno SA, Urban N, Yi B, Niebuhr DW. Musculoskeletal injuries among overweight army trainees: incidence and health care utilization. Occup Med (Lond). 2011 Jun;61(4):247-52.

3 Smith TA, Cashman TM. The incidence of injury in light infantry soldiers. Mil Med. 2002 Feb;167(2):104-8.

4 Teyhen DS, Goffar SL, Shaffer SW, Kiesel K, Butler RJ, Tedaldi AM, et al. Incidence of musculoskeletal injury in US Army unit types: a prospective cohort study. J Orthop Sports Phys Ther. 2018 Oct;48(10):749-57.

5 Knapik JJ, Canham-Chervak M, Hauret K, Hoedebecke E, Laurin MJ, Cuthie J. Discharges during U.S. Army basic training: injury rates and risk factors. Mil Med. 2001 Jul;166(7):641-7. 
Hollander et al.: Body Mass Index and Overuse Injuries in Israel Defense Forces

6 Bulzacchelli MT, Sulsky SI, Rodriguez-Monguio R, Karlsson LH, Hill MO. Injury during U.S. Army basic combat training: a systematic review of risk factor studies. Am J Prev Med. 2014 Dec;47(6):813-22.

7 Schwartz 0, Levinson T, Astman N, Haim L. Attrition due to orthopedic reasons during combat training: rates, types of injuries, and comparison between infantry and noninfantry units. Mil Med. 2014 Aug;179(8):897-900.

8 Havenetidis K, Paxinos T. Risk factors for musculoskeletal injuries among Greek Army officer cadets undergoing Basic Combat Training. Mil Med. 2011 Oct;176(10):1111-6.

9 Taanila H, Suni J, Pihlajamäki H, Mattila VM, Ohrankämmen O, Vuorinen P, et al. Aetiology and risk factors of musculoskeletal disorders in physically active conscripts: a follow-up study in the Finnish Defence Forces. BMC Musculoskelet Disord. 2010 Jul;11(1):146.

10 Kollock RO, Andrews C, Johnston A, Elliott T, Wilson AE, Games KE, et al. A meta-analysis to determine if lower extremity muscle strengthening should be included in military knee overuse injury-prevention programs. J Athl Train. 2016 Nov;51(11):919-26.

11 Finestone AS, Eshel A, Milgram C, Katz G, Constantini N. Components of weight gain during infantry training. J Isr Mil Med. 2009;6(2):72-5.

12 Murphy DF, Connolly DA, Beynnon BD. Risk factors for lower extremity injury: a review of the literature. Br J Sports Med. 2003 Feb;37(1):13-29.

13 Arnold M, Pandeya N, Byrnes G, Renehan PA, Stevens GA, Ezzati PM, et al. Global burden of cancer attributable to high body-mass index in 2012: a population-based study. Lancet Oncol. 2015 Jan;16(1):36-46.

14 Bhaskaran K, Douglas I, Forbes H, dos-Santos-Silva I, Leon DA, Smeeth L. Body-mass index and risk of 22 specific cancers: a population-based cohort study of 5.24 million UK adults. Lancet. 2014 Aug;384(9945): 755-65.

15 Twig G, Tirosh A, Leiba A, Levine H, Ben-Ami Shor D, Derazne E, et al. BMI at age 17 years and diabetes mortality in midlife: a nationwide cohort of 2.3 million adolescents. Diabetes Care. 2016 Nov;39(11):19962003.

16 Twig G, Yaniv G, Levine H, Leiba A, Goldberger N, Derazne E, et al. Body mass index in 2.3 million adolescents and cardiovascular death in adulthood. New Engl J Med. 2016;374(25):2430-40.

17 Twig G, Afek A, Shamiss A, Derazne E, Rabbi ML, Tzur D, et al. Adolescence BMI and trends in adulthood mortality: a study of 2.16 million adolescents. J Clin Endocrinol Metab. 2014;99(6):2095-103.

18 Twig G, Geva N, Levine H, Derazne E, Goldberger N, Haklai Z, et al. Body mass index and infectious disease mortality in midlife in a cohort of 2.3 million adolescents. Int J Obes. 2018 Apr;42(4):801-7.

19 Twig G, Vivante A, Bader T, Derazne E, Tsur AM, Levi M, et al. Body Mass Index and kidney disease-related mortality in midlife: A nationwide cohort of 2.3 million adolescents. Obesity (Silver Spring). 2018 Apr;26(4): 776-81.

20 Meo SA, Altuwaym AA, Alfallaj RM, Alduraibi KA, Alhamoudi AM, Alghamdi SM, et al. Effect of obesity on cognitive function among school adolescents: a cross-sectional study. Obes Facts. 2019;12(2):150-6.

21 Tsao Y, Chen J, Yeh W, Li W. Gender- and age-specific associations between visceral obesity and renal function impairment. Obes Facts. 2019;12(1):67-77.

22 Kim JE, Hsieh MH, Shum PC, Tubbs RS, Allison DB. Risk and injury severity of obese child passengers in motor vehicle crashes. Obesity (Silver Spring). 2015 Mar;23(3):644-52.

23 Kuczmarski RJ, Flegal KM. Criteria for definition of overweight in transition: background and recommendations for the United States. Am J Clin Nutr. 2000 Nov;72(5):1074-81.

24 Taanila H, Suni JH, Kannus P, Pihlajamäki H, Ruohola JP, Viskari J, et al. Risk factors of acute and overuse musculoskeletal injuries among young conscripts: a population-based cohort study. BMC Musculoskelet Disord. 2015 May;16(104):104.

25 Chassé M, Fergusson DA, Chen Y. Body mass index and the risk of injury in adults: a cross-sectional study. Int J Obes. 2014 Nov;38(11):1403-9.

26 Bar Dayan Y, Elishkevits K, Grotto I, Goldstein L, Goldberg A, Shvarts S, et al. The prevalence of obesity and associated morbidity among 17-year-old Israeli conscripts. Public Health. 2005 May;119(5):385-9.

27 Smith TJ, Marriott BP, Dotson L, Bathalon GP, Funderburk L, White A, et al. Overweight and obesity in military personnel: sociodemographic predictors. Obesity (Silver Spring). 2012 Jul;20(7):1534-8.

28 Department of Defense, USA. Demographic profile of the military community, 2016 [Internet] [cited 2018 Oct 22]. Available from: https://download.militaryonesource.mil/12038/MOS/Reports/2016-DemographicsReport.pdf

29 Yanovich R, Friedman E, Milgrom R, Oberman B, Freedman L, Moran DS. Candidate gene analysis in israeli soldiers with stress fractures. J Sports Sci Med. 2012 Mar;11(1):147-55.

30 Tsur AM, Rivkin V, Koren L, Frenkel H, Abramovitch E. Differences in anthropometric measures among military service candidates between screening and day of recruitment. J Isr Milit Med. 2019;16:16-21.

31 Bar-Dayan Y, Morad Y, Elishkevitz KP, Bar-Dayan Y, Finestone AS. Back disorders among Israeli youth: a prevalence study in young military recruits. Spine J. 2012 Sep;12(9):749-55.

32 Israel Central Bureau of Statistics. Local councils and municipalities by socio-economic index, ranking and cluster membership 2017 [Internet] [cited 2018 Oct 22]. Available from: http://www.cbs.gov.il/publications/ local_authorities06/pdf/t02.pdf

33 Hales CM, Fryar CD, Carroll MD, Freedman DS, Ogden CL, David S, et al. Trends in obesity and severe obesity prevalence in US youth and adults by sex and age, 2007-2008 to 2015-2016. JAMA. 2018 Apr;319(16): 1723-5. 
34 Hendrix CG, Prins MR, Dekkers H. Developmental coordination disorder and overweight and obesity in children: a systematic review. Obes Rev. 2014 May;15(5):408-23.

35 Pagoto SL, Curtin C, Lemon SC, Bandini LG, Schneider KL, Bodenlos JS, et al. Association between adult attention deficit/hyperactivity disorder and obesity in the US population. Obesity (Silver Spring). 2009;17(3):539-44.

36 Toschke A, Ludde R, Eisele R, Von Kries R. The obesity epidemic in young men is not confined to low social classes - a time series of 18-year-old German men at medical examination for military service with different educational attainment. Int J Obes (Lond). 2005;29(7):875-7.

37 Hauret KG, Jones BH, Bullock SH, Canham-Chervak M, Canada S. Musculoskeletal injuries description of an under-recognized injury problem among military personnel. Am J Prev Med. 2010 Jan;38(1 Suppl):S61-70.

38 Finestone AS, Milgrom C, Yanovich R, Evans R, Constantini N, Moran DS. Evaluation of the performance of females as light infantry soldiers. BioMed Res Int. 2014;2014:572953.

39 Kaufman KR, Brodine S, Shaffer R. Military training-related injuries: surveillance, research, and prevention. Am J Prev Med. 2000 Apr;18(3 Suppl):54-63.

40 Amorim AB, Ferreira PH, Ferreira ML, Lier R, Simic M, Pappas E, et al. Influence of family history on prognosis of spinal pain and the role of leisure time physical activity and body mass index: a prospective study using family-linkage data from the Norwegian HUNT study. BMJ Open. 2018 Oct;8(10):e022785.

41 Janke EA, Collins A, Kozak AT. Overview of the relationship between pain and obesity: what do we know? Where do we go next? J Rehabil Res Dev. 2007;44(2):245-62.

42 Davillas A, Benzeval M. Alternative measures to BMI: exploring income-related inequalities in adiposity in Great Britain. Soc Sci Med. 2016 Oct;166:223-32.

43 Ketko I, Hadid A, Yanovich R, Epstein Y, Heled Y. The load carriage index (LCI) - adjusting the load carried by the soldier according to body composition measurements. Extrem Physiol Med. 2015;4(1 Suppl 1):A10.

44 Knapik JJ, Sharp MA, Montain SJ. Association between stress fracture incidence and predicted body fat in United States Army Basic Combat Training recruits. BMC Musculoskelet Disord. 2018 May;19(1):161.

45 Milgrom C, Giladi M, Simkin A, Rand N, Kedem R, Kashtan H, et al. The area moment of inertia of the tibia: a risk factor for stress fractures. J Biomech. 1989;22(11-12):1243-8.

46 Finestone A, Shlamkovitch N, Eldad A, Wosk J, Laor A, Danon YL, et al. Risk factors for stress fractures among Israeli infantry recruits. Mil Med. 1991 Oct;156(10):528-30.

47 Havenetidis K, Paxinos T, Kardaris D, Bissas A. Prognostic potential of body composition indices in detecting risk of musculoskeletal injury in army officer cadet profiles. Phys Sportsmed. 2017 May;45(2):114-9. 